\title{
Phylogenetic analysis of the allometric scaling of therapeutic regimes for birds
}

\author{
A. P. Kabat ${ }^{1}$, T. M. Blackburn ${ }^{2}$, A. E. McKechnie ${ }^{3}$ \& P. J. Butler ${ }^{1}$
}

1 Centre for Ornithology, School of Biosciences, University of Birmingham, Birmingham, UK

2 Institute of Zoology, Zoological Society of London, London, UK

3 Department of Zoology and Entomology, DST/NRF Centre of Excellence at the FitzPatrick Institute, University of Pretoria, Pretoria, South Africa

\section{Correspondence}

A. P. Kabat, Centre for Ornithology, School of Biosciences, University of Birmingham, Edgbaston, Birmingham, B15 2TT, UK. Tel: +44 (0) 121414 3822; Fax: +44 (0) 1214145925

Email: Alexander.Kabat@gmail.com

\begin{abstract}
The use of allometric scaling to estimate drug doses, regimes, and clearance rates (metabolic dosing) is based on the principle that the amount of drug to be administered is more closely related to daily energy use than to body mass $(\mathrm{kg})$. Thus, by using the allometric estimations of minimal energy consumption (MEC) in kcal day ${ }^{-1}$ based on the formula $\mathrm{MEC}=\mathrm{kM}_{\mathrm{b}}{ }^{\mathrm{b}}$, where $\mathrm{b}=3$, it is thought to be possible to extrapolate appropriate drug dosage regimens to species for which direct MEC data are unavailable. However, the allometric equations for respiratory variables in birds were developed 30 years ago, and were based on a very small sample size, while the appropriate scaling exponent for the allometry of energy use is a matter of considerable debate. Hence, we revisit the issue of the scaling of therapeutic regimes in birds using the most current expanded database available (resting metabolic rate data for 296 species across 17 bird orders), taking account of the non-independence of species in this process using a phylogenetically independent approach. We show that the use of caloric values to estimate daily energy consumption introduces significant error into the formula, as there are a number of assumptions that are made when converting rate of oxygen consumption to a caloric value. We also show that there are significant differences in the proportionality or Hainsworth coefficients k across taxa when the data are examined in a phylogenetic context, although the allometric scaling exponent does not vary. We therefore recommend the use of only data based on oxygen consumption values, and not caloric values, and a multi-order phylogenetic model when calculating the appropriate drug dosage regime.
\end{abstract}




\section{Introduction}

Early in the last century, comparative physiologists measured the basal metabolic rates (BMR in terms of $\mathrm{mL} \mathrm{O}_{2} \mathrm{~min}^{-1}$ ) or minimum energy consumption (MEC in terms of kcal day ${ }^{-1}$ ) of many vertebrate species (Brody, 1945; Kleiber, 1932 as cited in Kleiber, 1975). The BMR or MEC is the minimal amount of energy that an animal, which is non-reproductive, at rest, during the inactive part of the day, post-digestive, and non-thermoregulatory, requires to maintain life (Withers, 1992; McNab, 1997). It has been shown that across the vast majority of terrestrial vertebrates, basal metabolism is linearly proportional to body mass when both are plotted on logarithmic axes. This means that basal metabolism is a power function of body mass $\left(\mathrm{M}_{\mathrm{b}}\right)$, such that $\mathrm{BMR}=\mathrm{aM}_{\mathrm{b}}{ }^{\mathrm{b}}$ where ' $\mathrm{b}$ ' is the scaling exponent and ' $\mathrm{a}$ ' is termed the, 'proportionality (normalization) coefficient' in the scaling literature or the 'Hainsworth constant, $\mathrm{k}^{\prime}$ in the pharmacokinetic literature in terms of kcal day ${ }^{-1}$ (cited in Wolfensohn \& Lloyd, 2007). It is also important to note that ' $k$ ' (a) is not actually a constant and can vary due to a host of influences.

The effect of body mass on metabolic rate was first suggested over 160 years ago by Sarrus \& Rameaux (1838). Subsequently, Max Rubner's 1883 (cited in Kleiber, 1975) research showed proportionality between metabolic rate and body surface area. Later, Max Kleiber's influential paper (Kleiber, 1932) reported that metabolic rate was more closely proportional to the allometric equation $\mathrm{MR} \mathrm{M}_{\mathrm{b}}{ }^{3 / 4}$, and this view has persisted until the present time. However, what is the most accurate scaling exponent remains a contentious issue. Exceptions to the ubiquity of the 3/4-power metabolic scaling exponent have been reported for insects, fish, amphibians, birds and mammals (White \& Seymour, 2004; White, Phillips \& Seymour, 2006; Chown et al., 2007). Indeed, the results of two recent meta-analyses failed to find support for a universal metabolic scaling exponent of 3/4 (Glazier, 2005; White et al., 2007).

The proportionality coefficients indicate inter-taxon variation in the elevation of the allometric relationship. The proportionality (Hainsworth ' $k$ ') coefficients used in the traditional MEC model $\left(\mathrm{MEC}_{\text {traditional }}=\mathrm{kM}_{\mathrm{b}}{ }^{\mathrm{b}} \mathrm{kcals} \mathrm{day}^{-1}\right.$ ) for five major taxa at their optimal body temperature are: passerine birds $\mathrm{k}=129$, non-passerine birds $\mathrm{k}=78$, placental mammals $\mathrm{k}=70$, marsupial mammals $\mathrm{k}=49$ and reptiles $\mathrm{k}=10$. Hence, the $\mathrm{MEC}_{\text {traditional }}$ formula for passerines and non-passerines would $=129 \mathrm{M}_{\mathrm{b}}{ }^{3 / 4}$ and $78 \mathrm{M}_{\mathrm{b}}^{3 / 4} \mathrm{kcals} \mathrm{day}^{-1}$, respectively (Sedgwick, Pokras \& Kaufman, 1990).

Allometric scaling relationships are used to estimate drug doses, regimes and clearance rates (i.e. metabolic dosing), based on the principle that the amount of drug that needs to be administered to an animal is related to its daily energy use more closely than to its body mass (Sedgwick et al., 1990). By using the allometric estimations derived from the $\mathrm{MEC}_{\text {traditional }}$ formula (MR in $\mathrm{kcals} \mathrm{day}^{-1}=\mathrm{kM}_{\mathrm{b}}{ }^{3 / 4}$ ), it is believed to be possible to extrapolate the daily energy and nutrient requirements and appropriate drug dosage regimens across species. However, the value of allometry for predictive purposes for pharmacological dosing regimes has been the subject of continued scepticism. For example, discussing the factors influencing pharmacokinetic variation, Baggot (1982) wrote '... the only conclusion that can be drawn is that pharmacological half-life should not be extrapolated from one species to another'. 
Most formularies are based on mammals, predominantly using data from humans. The limited pharmacological information for birds is based on information derived from studies in poultry, parrots or pigeons. Extrapolating dosing regimes using allometric scaling from mammals and domestic poultry to other avian species is complicated and has its limits. Most birds have a high mass-specific metabolic rate compared with mammals (Suarez, 1996), but this is not the case for domestic poultry (Lasiewski \& Dawson, 1967). The relatively high MR exhibited by most bird taxa makes an accurate dosage of therapeutics very important. Lasiewski \& Calder (1971) derived the allometric equation for metabolic rate used for estimating dosing regimes in birds over 30 years ago. This study was based on only six species, and was presented as a 'preliminary' research finding because of the small number of species. However, the outcome of this study is widely used as a definitive equation.

Several recent papers have investigated the allometry of birds and have shown that a range of factors influences the value of the exponent (Frappell, Hinds \& Boggs, 2001; McKechnie, Freckleton \& Jetz, 2006; White et al., 2007). One key issue is that species do not comprise independent data points for statistical analysis due to their inter-relatedness. The hierarchical nature of evolutionary relationships means that closely related species are more likely to resemble each other than are distantly related species (Harvey \& Pagel, 1991). Thus, trait values of species can be predicted from the values taken by their close relatives. Yet, an assumption of standard statistical tests is that data points are independent (the value of one data point cannot be predicted from the value taken by another). This has several important consequences for analyses exploring allometric relationships (for further discussion, see Halsey, Butler \& Blackburn, 2006). From the perspective of the current study, a failure to incorporate information on the relatedness of species can lead to estimates of dosing regimes that are biased and inaccurate.

In order to investigate the accuracy of the current metabolic dosing regime model, the present paper investigates the allometric equation for birds using the most up to date expanded database now available (BMR data for 296 species across 17 bird orders), in a phylogenetic framework. This involves a review of all known literature that investigates the BMR of birds. We also explore several of the major assumptions made by the dosing regime model.

\section{Methods}

Although the International System of Units (SI) uses joules (or kilojoules) to describe the units of metabolic energy, the current model employed by veterinary clinicians to calculate allometric dosing regimes uses the calorie (or kilocalorie) unit $(4.2 \mathrm{~kJ}=1 \mathrm{kcal})$ and therefore, to retain clinical relevance, this paper will use the calorie unit.

Body mass $\left(\mathrm{M}_{\mathrm{b}}\right.$, in $\left.\mathrm{kg}\right)$ and $\mathrm{BMR}\left(\mathrm{mL} \mathrm{O}_{2} \mathrm{~min}^{-1}\right)$ data were collected from the published literature that investigates the energetics of birds. Papers were assessed on the basis of the following factors: age of animal, temperature at testing, habitat temperature and time of year (as this can have a major impact on metabolic rate), whether the birds were wild or captive bred, and if wild, the length of time in captivity. Only data on unanaesthetized birds, breathing air (no special gas mixes) and 
within their thermoneutral zone, were accepted into the dataset. A study was rejected if the animals were measured during the feather moult or reproductive seasons. If birds were wild captured, only studies from animals that were in captivity for more than $48 \mathrm{~h}$ but $<10$ days were used. The collated metabolic rates and body masses were evaluated using a traditional approach, which employed a least squares regression technique following $\log _{10}$ transformation of the data to obtain a power equation in the form $\mathrm{y}=\mathrm{kM}_{\mathrm{b}}{ }^{\mathrm{b}}$. To equate $\mathrm{MEC}_{\text {measured }}$ with the current dosing allometric standard predictive methods, BMR values were transformed into $\mathrm{kcal}^{-1} \mathrm{y}^{-1}$ using the conversion factor of $4.8 \mathrm{kcal} \mathrm{L}^{-1} \mathrm{O}_{2}$, assuming a respiratory exchange rate of 0.7 (resting energy substrate utilization that is oxidation of fatty acids, see SchmidtNielsen, 1997). MEC $_{\text {traditional }}$ was calculated by using the current allometric dosing model formula for passerines and non-passerines $\left(\mathrm{MEC}_{\text {traditional }}=129 \mathrm{M}_{\mathrm{b}}{ }^{3 / 4}\right.$ and $78 \mathrm{M}_{\mathrm{b}}{ }^{3 / 4} \mathrm{kcals}$ day $^{-1}$, respectively).

Mass and BMR data for 346 data points from 296 species across 17 bird orders were assembled. Eight of the orders included four species or fewer, and only seven orders had data for more than 10 species. Hence, the data were analysed twice using phylogenetically informed analyses, once using only orders with 10 or more species, and once using orders with more than five species. The first analysis utilized 316 data points, comprising seven orders. The second analysis utilized 326 data points, comprising nine orders.

The method of phylogenetic generalized least squares (PGLS) was used to address the issue of phylogenetic non-independence (for a more detailed discussion of the PGLS method in the context of physiology, see Halsey et al., 2006; White et al., 2007), because current evidence shows that metabolic rates are not statistically independent for related species (see Freckleton, Harvey \& Pagel, 2002; Blomberg, Garland \& Ives, 2003; Rezende, Bozinovic \& Garland, 2004). The PGLS analysis was performed in R v 2.3.1 (Ihaka \& Gentleman, 1996) using the Analysis of Phylogenetics and Evolution (APE) package (Paradis, Claude \& Strimmer, 2004) with code written by R. P.

Duncan (see Halsey et al., 2006). The phylogeny of Sibley \& Ahlquist (1990) was used to construct a phylogenetic hypothesis, with genera assigned to higher taxa as described in Sibley \& Monroe (1990). All branches in the model were set as equal, as many of the branch lengths in the phylogeny are not definitively known (see McKechnie et al., 2006; White et al., 2007). However, results were very similar under an alternative assumption that branch lengths were proportional in length to the number of taxa descended from the node to which the branch leads (Grafen, 1989); these two alternatives model punctuational and gradual modes of evolution, respectively.

Five statistical models of variation in avian BMR were analysed (Table 1). All of these included mass as a covariate, but they differed in terms of how the avian phylogeny is included as a factor. The simplest model analysed all birds together, and hence includes only mass as a predictor variable (LogMass). This is compared with models that specify separate intercepts for passerines and non-passerines (LogMass+Pass/Nonpass), separate slopes and intercepts for passerines and nonpasserines (LogMass+Pass/Nonpass+LogMass:PNP), separate intercepts for different orders (LogMass+Order), and separate slopes and intercepts for different orders (LogMass+Order+LogMass:Order). The framework set forth by Burnham \& Anderson (2001) for model comparison was used to identify the most plausible 
model(s) for MEC. This framework was based on the calculated value of Akaike's Information Criterion (AIC) as a measure of model fit (Burnham \& Anderson, 2001, 2002). The AIC value was calculated as -2 times the log-likelihood of the model, +2 times the number of estimable parameters (Burnham \& Anderson, 2001). The latter term penalizes unnecessary parameters in the model, such that the best-fit model excludes a parameter if it explains little variance in the data. The best model of any candidate set applied to a given dataset is that with the lowest AIC value. Models with $\mathrm{AIC}<2$ greater than the best model can be considered reasonable alternatives to the best model, while a difference in AIC $>10$ indicates that the model with the higher AIC is a poor alternative. The probability that a model is actually the best-fit out of those tested was measured by its Akaike weight, $\left(\omega_{i}\right.$, the likelihood of the model divided by the sum of the likelihoods of all other models; Burnham \& Anderson, 2001).

Table 1 AIC, $\lambda$ and $\omega_{\mathrm{i}}$ of the five models tested for the 316 species separated into seven phylogenetic orders

\begin{tabular}{llll}
\hline Model & AlC & $\lambda$ & $\omega_{i}$ \\
\hline LogMass & -494.91 & 0.85 & 0.003 \\
LogMass + Pass/Nonpass & -502.10 & 0.79 & 0.111 \\
LogMass + Pass/Nonpass + LogMass:PNP & -501.01 & 0.79 & 0.064 \\
LogMass+ Order & -506.13 & 0.68 & 0.822 \\
LogMass+ Order+LogMass:Order & -486.30 & 0.00 & 0.000 \\
\hline
\end{tabular}

AIC, Akaike's Information Criterion.

Once the best models were identified (see 'Results'), ANOVA was used to test whether there were differences in the energy costs measured for the species in our data, and the costs predicted from different models. Specifically, we tested for differences between the following six sets of values: $\mathrm{MEC}_{\text {measured }}$ versus MEC calculated using traditional exponential values ( $\left.\mathrm{MEC}_{\text {traditional }}\right), \mathrm{MEC}_{\text {measured }}$ versus MEC calculated using the seven-order phylogenetically corrected model $\left(\mathrm{MEC}_{\text {seven }}\right.$ order), $\mathrm{MEC}_{\text {measured }}$ versus $\mathrm{MEC}$ calculated using the two-order (passerines vs. nonpasserines) phylogenetically corrected model $\left(\mathrm{MEC}_{\text {two order }}\right), \mathrm{BMR}_{\text {measured }}$ versus $\mathrm{BMR}$ calculated using traditional exponential values $\left(\mathrm{BMR}_{\text {traditional }}\right), \mathrm{BMR}_{\text {measured }}$ versus BMR calculated using the seven-order phylogenetically corrected model $\left(\mathrm{BMR}_{\text {seven }}\right.$ order), and $\mathrm{BMR}_{\text {measured }}$ versus BMR calculated using the two-order phylogenetically corrected model (BMR two order $)$. The doses of two commonly prescribed antibiotics, amikacin and amoxycil/clavulan, were also calculated using the different energy use models. We then performed the same six sets of comparisons testing for differences in dose $\left(\mathrm{mg} \mathrm{kg}^{-1}\right)$ calculated from measured energy use values $\left(\mathrm{MEC}_{\text {measured, }}\right.$, $\left.\mathrm{BMR}_{\text {measured }}\right)$ and from energy use values calculated from various models $\left(\mathrm{MEC}_{\text {traditional }}, \mathrm{MEC}_{\text {seven order }}, \mathrm{MEC}_{\text {two order }}, \mathrm{BMR}_{\text {traditional }}, \mathrm{BMR}_{\text {seven order }}, \mathrm{BMR}_{\text {two order }}\right)$. Note that when using a general linear model such as ANOVA to test the fit of a predictive model to measured data, significant differences equal a poor fit, and so the lower the $\mathrm{F}$ value (or the larger the $\mathrm{P}$ value), the better the predictive value (Zar, 1999). To test for homogeneity of the data the means of residuals were compared using a least squares regression analysis and the difference between predicted and 
measured values was analysed with repeated measures ANCOVA using mean mass as the covariate.

\section{Results}

Traditional ordinary least squares analysis of log BMR against LogMass for all 296 species across 17 bird (Supplementary Material Appendix S2) orders identifies a model with a slope (allometric exponent) of 0.68 and an intercept (Hainsworth constant) of 0.11 (Fig. 1). LogMass explains $93 \%$ of the variance in $\log$ BMR, and the $95 \%$ confidence intervals $(\mathrm{CI})$ of the regression slope encompass 0.667 but not 0.75 . The PGLS analysis of the same data, that incorporates information on the phylogenetic relatedness of the species, identifies a model with a slope of 0.71 and an intercept of 0.08 . The $95 \%$ CI of the slope estimate span the range $0.681-0.746$, and so do not encompass 0.667 or 0.75 . AIC for the OLS model is -374.3 , whereas for the PGLS model it is -498.0 . Thus, on the basis of their relative likelihoods as indicated by their AICs, the probability that the standard model, taking no account of phylogeny, is the better fit out of the two is $<1 \times 10^{-26}$. All subsequent allometric analyses use the PGLS method.

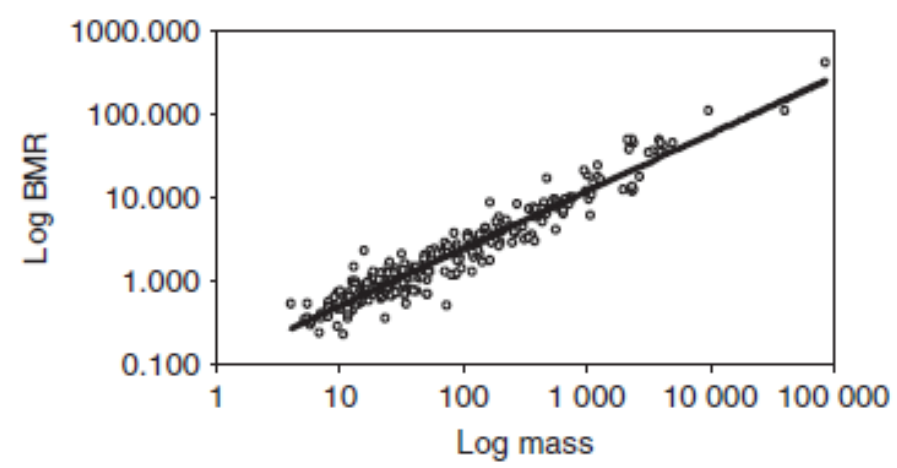

Figure 1 Log-log plot of basal metabolic rates (BMR, $\mathrm{mL} \mathrm{O}_{2} \mathrm{~min}^{-1}$ ) versus mass of 296 bird species across 17 orders $\left(y=0.11 x^{0.68}, r^{2}=0.93\right)$. The regression line is from a traditional ordinary least squares model treating species as independent data points. Mass is in $\mathrm{kg}$.

The analysis that excluded orders with fewer than 10 species $(n=316$, comprising seven orders) identifies the best model as LogMass+Order, with an $\omega_{i}$ value of 0.822 . This model has a common slope \pm standard error of $0.73 \pm 0.02$ and intercepts that differ across orders, and will henceforth be called the seven-order phylogenetic model (Fig. 2; Table 1). The seven-order phylogenetic model shows that the coefficients differ across orders, yielding significantly different intercepts (Table 2; ANCOVA: $\left.\mathrm{F}_{1,6}=45.25, \mathrm{P}<0.001\right)$. A Tukey's HSD showed that the differences lay between Anseriformes and all other orders, Passeriformes and all other orders, and between Ciconiiformes and Anseriformes and Passeriformes, but no other orders. The 95\% CI for the common slope encompass 0.75 but not 0.67 . 


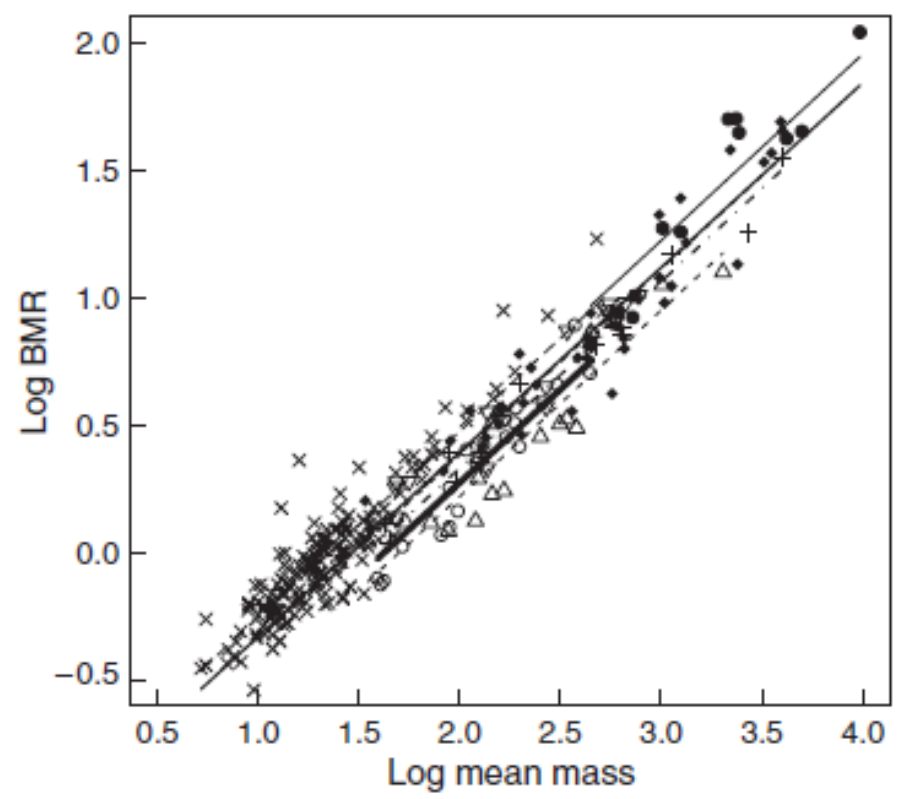

Figure 2 Phylogenetically treated $\log -\log$ plot of basal metabolic rates (BMR, $\mathrm{mL} \mathrm{O}_{2} \mathrm{~min}^{-1}$ ) versus mass of 296 species of birds, comprising seven orders. The solid line through the entire data is the overall regression line through all data; shorter lines relate to individual orders. Pluses, Galliformes; filled circles, Anseriformes; inverted triangles, Psittaciformes; triangles, Strigiformes; open circles, Columbiformes; diamonds, Ciconiiformes; crosses, Passeriformes. Mass is in $\mathrm{kg}$.

Table 2 Seven-order phylogenetic model, showing predicted log-log coefficients and corresponding intercepts (k constant) \pm standard error $(\mathrm{se})$

\begin{tabular}{llll}
\hline Orders & Coefficient & $k$ & SE \\
\hline Anseriformes & -0.97 & 0.11 & 0.081 \\
Ciconifformes & -1.08 & 0.08 & 0.010 \\
Columbiformes & -1.19 & 0.07 & 0.097 \\
Galliformes & -1.13 & 0.07 & 0.069 \\
Passeriformes & -0.98 & 0.10 & 0.099 \\
Psittaciformes & -1.07 & 0.08 & 0.089 \\
Strigiformes & -1.24 & 0.06 & 0.096 \\
\hline
\end{tabular}

The analysis that excluded orders with fewer than five species $(n=326$, comprising nine orders) shows that the best-fit model is LogMass+Pass/Nonpass with a $\omega_{i}$ value of 0.590. This model has a common slope but intercepts that differ between passerines and non-passerines, and will henceforth be called the two-order phylogenetic model. The common slope for the model is $0.726 \pm 0.02$ (Table 3), with $95 \%$ CI that encompass 0.75 but not 0.67 . The next best model in this data also includes an interaction term for LogMass and Pass/Nonpass, and has a $\omega_{\mathrm{i}}$ value of 0.259 . The slope for passerines in this model is 0.716 (95\% CI: $0.641-0.790$ and that for nonpasserines is 0.731 (95\% CI: $0.691-0.770)$. The difference in AIC values between these two models is $<2$, indicating that both are reasonable candidate models for this dataset, although clearly the model without the interaction term is more likely. The 
two-order phylogenetic model has intercepts that differ between the passerine and non-passerine birds investigated (Table 4; ANOVA: $\mathrm{F}_{1,2}=35.12, \mathrm{P}=0.001$ ).

Table 3 AIC, $\lambda$ and $\omega_{\mathrm{i}}$ of the five models tested for the 326 species separated into nine phylogenetic orders

\begin{tabular}{llll}
\hline Model & AlC & $\lambda$ & $\omega_{i}$ \\
\hline LogMass & 500.03 & 0.87 & 0.044 \\
LogMass + Pass/Nonpass & 505.23 & 0.84 & 0.590 \\
LogMass + Pass/Nonpass + LogMass:PNP & 503.58 & 0.84 & 0.259 \\
LogMass + Order & 498.31 & 0.00 & 0.018 \\
LogMass + Order + LogMass:Order & 501.45 & 0.00 & 0.089 \\
\hline
\end{tabular}

AIC, Akaike's Information Criterion.

Table 4 Two-order phylogenetic model, showing predicted log-log coefficients and corresponding intercepts ( $\mathrm{k}$ constants) \pm standard error (se)

\begin{tabular}{llll}
\hline Intercepts & Coefficient & $k$ values & SE \\
\hline Non-passerines & -1.085 & 0.08 & 0.059 \\
Passerines & -0.928 & 0.12 & 0.056 \\
\hline
\end{tabular}

The model comparing the mean measured daily caloric consumption ( $\left.\mathrm{MEC}_{\text {measured }}\right)$ to that estimated using the traditional allometric method $\left(\mathrm{MEC}_{\text {traditional }}\right)$ reveals significant differences between estimated and calculated values for both passerine and non-passerine birds (Fig. 3a: ANOVA: $\mathrm{F}_{1,4391}=9.14, \mathrm{P}=0.02$ ). Differences between measured and calculated MEC values were also observed with the MEC calculated using the two-order model (ANOVA: $\mathrm{F}_{1,204}=1.86, \mathrm{P}=0.04$ ) and the seven-order model (ANOVA: $\mathrm{F}_{1,627}=1.31, \mathrm{P}=0.05$ ). Therefore, none of the three models accurately predict MR using the MEC method. 

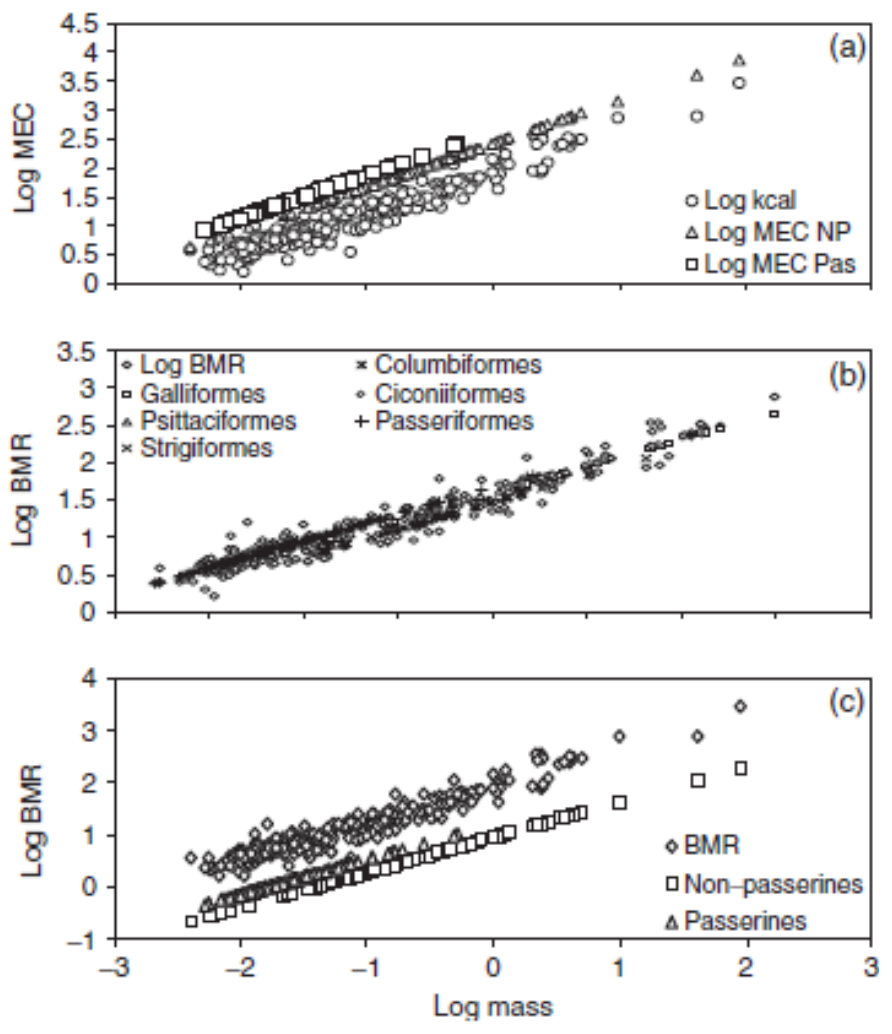

Figure 3 (a) Regression of the log predicted values of minimum energy costs $\left(\mathrm{MEC}_{\text {traditional }}\right)$ and $\mathrm{MEC}_{\text {measured }}$ against LogMass for passerine $(\Delta=\log \mathrm{MEC} \mathrm{P})$ and non-passerine birds ( $\square=\log$ MEC NP) as well as measured BMR expressed in daily kilocalories ( $\mathrm{O}=\log \mathrm{MEC} \mathrm{kcal}$ ) assuming a predominately lipid metabolism. (b) Regression plot of the log 7-order phylogenetic model estimated basal metabolic rates (BMR $\mathrm{mL} \mathrm{O}_{2} \mathrm{~min}^{-1}$ ) and actual measured BMR versus LogMass. (c) Regression plot of the log 2-order phylogenetic model estimated BMR and actual measured BMR versus LogMass for passerine and non-passerine birds. Mass is in $\mathrm{kg}$.

There is a significant difference (ANOVA: $\mathrm{F}_{1,156}=16.64, \mathrm{P}<0.001$ ) between measured BMR values $\left(\mathrm{BMR}_{\text {measured }}\right)$ and those estimated by the traditional allometric method for birds when using traditional formulae $\left(\mathrm{BMR}_{\text {traditional }}\right.$; formula for non-passerines: $\mathrm{y}=9.28 \mathrm{M}_{\mathrm{b}}{ }^{0.75}$; formula for passerines: $\left.\mathrm{y}=16.31 \mathrm{M}_{\mathrm{b}}{ }^{0.75}\right)$. There was also a significant difference between BMR values estimated using the two-order phylogenetic model $\left(\mathrm{BMR}_{\mathrm{two} \text { order }}\right)$ and $\mathrm{BMR}_{\text {measured }}$ (Fig. 3c; ANOVA: $\left.\mathrm{F}_{1,185}=19.74, \mathrm{P}<0.001\right)$. There was, however, no significant difference between the model comparing $\mathrm{BMR}_{\text {measured }}$ and $\mathrm{BMR}_{\text {seven order }}$ (Fig. 3b; ANOVA: $\mathrm{F}_{1,323}=0.35, \mathrm{P}=0.57$ ), suggesting that this model most accurately predicts the rate of energy consumption for birds.

The dose regime models for amikacin and amoxycil/clavulan (Table 5) suggest that there are significant differences in the dose required calculated directly from $\mathrm{MEC}_{\text {measured }}$ from those estimated using the traditional formulae $\left(\mathrm{MEC}_{\text {traditional }}\right.$ ANCOVA: $\mathrm{F}_{1,3}=7.19, \mathrm{P}=0.006$ ), $\mathrm{MEC}_{\text {seven order }}\left(\mathrm{ANOVA}: \mathrm{F}_{1,7}=47.75, \mathrm{P}<0.001\right.$ ) and $\mathrm{MEC}_{\text {two order }}\left(\mathrm{ANOVA}: \mathrm{F}=34.45_{1,3}, \mathrm{P}=0.005\right.$ ). The data also show that there are significant differences in the dose required if the dose is calculated directly from $\mathrm{BMR}_{\text {measured }}$ rather than estimated from $\mathrm{BMR}_{\text {two order }}\left(\mathrm{ANOVA}: \mathrm{F}_{1,3}=18.65, \mathrm{P}=0.039\right.$ ), as well as between the two-order phylogenetic model and the seven-order 
phylogenetic model (ANOVA: $\mathrm{F}_{1,7}=23.5 \mathrm{P}=0.047$ ). There was, however, no significant difference found between the dose regime calculated using $B M R_{\text {measured }}$ and that estimated from $\mathrm{BMR}_{\text {seven order }}\left(\mathrm{ANOVA}: \mathrm{F}_{1,3}=0.13, \mathrm{P}=0.68\right)$. This suggests that, in the absence of direct data on the BMR of a bird species, the seven-order phylogenetic model gives the most accurate dosing regime of those compared in the present study. Table 5 shows that the $\mathrm{MEC}_{\text {traditional }}$ model can overestimate the required drug dose by as much as $84 \%$ for non-passerines and $34 \%$ for passerines, when compared with that calculated using BMR.

Table 5 The per cent difference in required dose $\left(\mathrm{mg} \mathrm{kg}^{-1}\right)$ using values predicted by the $\mathrm{MEC}_{\text {calculated, }}$ two-order phylogenetic and seven-order phylogenetic models, compared with the actual measured mean minimum energetic values (MEC in kcal day ${ }^{-1}$; BMR in $\mathrm{mL} \mathrm{min}^{-1}$ )

\begin{tabular}{|c|c|c|c|c|c|}
\hline \multirow[b]{3}{*}{ Species } & \multirow{3}{*}{$\begin{array}{l}\text { Mean mass } \\
(\mathrm{kg}) \pm \text { SEM }\end{array}$} & \multicolumn{4}{|c|}{ Per cent difference from measured values } \\
\hline & & \multicolumn{2}{|c|}{$\mathrm{MEC}_{\text {calculated }}$ model } & \multicolumn{2}{|c|}{$\underline{B M R}$ from two-orders model } \\
\hline & & Amikacin & Amoxycil/Clavulan & Amikacin & Amoxycil/Clavulan \\
\hline Non-passerines & $0.85 \pm 0.12$ & 9.23 & 12.45 & 7.20 & 6.40 \\
\hline \multirow[t]{2}{*}{ Passerines } & $0.03 \pm 0.001$ & 34.25 & 32.11 & 9.45 & 7.24 \\
\hline & & & & \multicolumn{2}{|c|}{ BMR from seven-orders model } \\
\hline Anseriformes & $2.55 \pm 0.77$ & 84.15 & 69.48 & 8.25 & 5.65 \\
\hline Ciconiiformes & $0.91 \pm 0.18$ & 35.66 & 33.25 & 11.25 & 9.25 \\
\hline Columbiformes & $0.17 \pm 0.03$ & 19.25 & 12.35 & 6.54 & 5.04 \\
\hline Galliformes & $0.78 \pm 0.31$ & 25.37 & 15.33 & 14.32 & 1.26 \\
\hline Psittaciformes & $0.33 \pm 0.06$ & 35.63 & 29.52 & 2.26 & 12.32 \\
\hline Strigiformes & $0.36 \pm 0.11$ & 1.25 & 0.65 & 0.85 & 1.20 \\
\hline Passeriformes & $0.03 \pm 0.001$ & 10.25 & 13.55 & 5.24 & 6.12 \\
\hline
\end{tabular}

BMR, basal metabolic rate.

\section{Discussion}

The traditional allometric model for BMR plots the rate of oxygen consumption against body mass on double logarithmic axes, and assumes that all species are independent data points for the statistical comparison. This is equivalent to assuming that all species radiated from a single common ancestor, and so are all equally closely related. It also assumes that each species has evolved at an equal rate. However, we know that this is unlikely to be the case for any real clade consisting of more than two species. Incorporating phylogenetic information into the analysis of log BMR versus LogMass, using the method of PGLS, results in a model that is a substantially better fit to the data for birds. Indeed, the likelihood that the traditional allometric model for BMR is the better fit of the two is vanishingly small.

Further exploration of the allometry of metabolic rate using PGLS revealed that still better fits between model and data could be obtained by considering the distribution of bird species into subtaxa. Thus, when including only bird orders with data for more than 10 species ( $n=316$, seven orders), in order to maintain statistical power, the best model shows a common slope but intercepts that differ across the seven orders. The overall slope for the best model was $0.730 \pm 0.018$, and with different intercepts for each of the seven phylogenetic orders. When the model excluded only orders with fewer than five species ( $n=326$, nine orders), the best-fit model had a common slope of $0.726 \pm 0.017$, and different intercepts for passerines and non-passerines. This 
suggests that the best model for the allometry of avian BMR is somewhat sensitive to the composition of the dataset, but that in neither case is the best model one that considers all birds as a homogenous set with respect to the allometry of their BMR. Nevertheless, since the aim of our study was to attempt to identify the most appropriate model to use for the allometric scaling of dosing regimes, this sensitivity required us to test each predictive model against the actual measured value of energy consumption to assess which model has the least significant difference. The model with the least difference will be the most appropriate for calculating dosage regimes when, as will normally be the case, direct data on energy use for a species are lacking.

The traditional approach to allometric scaling of drug dosing relies on the use of daily minimum caloric consumption estimated by the MEC formula. The $\mathrm{MEC}_{\text {measured }}$ values presented in the present study were significantly different from those estimated by allometric equations, regardless of which model was used. This suggests that the assumptions used in the conversion from measured oxygen consumption to kilocalories are a major source of error. This is mostly likely due to the fact that in order accurately to estimate the kilocalorie value of metabolic rate, it is necessary to know what food substrates are being used and in what proportion. Often the substrate at rest is assumed to be purely lipid stores, which yields an energy value of $19.5 \mathrm{~kJ} \mathrm{~L} \mathrm{O}_{2}^{-1}\left(4.8 \mathrm{kcal} \mathrm{L} \mathrm{O}_{2}^{-1}\right)$. However, if the animal is using different proportions of carbohydrates and lipids, which is likely during times of physiological stress such as illness, the energy value could be as high as $21.4 \mathrm{~kJ} \mathrm{~L} \mathrm{O}_{2}^{-1}$ (assuming mostly carbohydrate).

A further problem with the traditional non-phylogenetic approach to the analysis of the effect of body size on respiratory variables is that it fails to account for the nonindependence of species (see e.g. Martins \& Hansen, 1997; Garland, Midford \& Ives, 1999). While the allometric exponents for BMR calculated from traditional nonphylogenetic models are here not significantly different from those using phylogenetically informed analyses, the latter approach broadens the confidence limits of the slope. The widening of the $95 \%$ CI to integrate both the 0.667 and 0.75 exponents when phylogeny is incorporated has been previously shown (Reynolds \& Lee, 1996; Ricklefs \& Starck, 1996), and is a consequence of properly accounting for the phylogenetic non-independence of the species (Martins \& Hansen, 1997; Garland $\&$ Ives, 2000). However, significant variation around the common slope can be accounted for by taxon membership (e.g. passerine vs. non-passerine, order), increasing the importance of the $\mathrm{k}$ coefficients (intercepts) for different taxonomic groups. As the coefficients differ significantly between groups, this will have a strong effect on estimates of energy consumption. This may explain the differences seen when comparing the values derived from the various models with the collated data. The analysis comparing the predicted and measured values of energy consumption demonstrated that the seven-order phylogenetic model provided the least difference between these two.

Obviously, in real-life situations, energy consumption will exceed this, especially if the animal is actively growing, attempting to heal, as after an injury or surgery or has a fever. Thus, using any scaling approach to determine dosing regimes will require a number of assumptions. These assumptions may introduce significant error into the estimations. In the process of transforming the rate of oxygen consumption data into caloric values per day $\left(\mathrm{kcal} \mathrm{day}^{-1}\right)$, as used by allometric formulae for drug dosing, an 
assumption about substrate metabolism has been made, which could have an impact on drug absorption.

When the traditional and phylogenetic models were ground tested by incorporating them into allometric dose calculations, it was found that the $\mathrm{MEC}_{\text {traditional }}$ model estimated significantly different doses from those obtained when using the direct $\mathrm{MEC}_{\text {measured }}$. This is not surprising, as $\mathrm{MEC}_{\text {traditional }}$ was shown significantly to overestimate the daily energy expenditure. The $\mathrm{MEC}_{\text {traditional }}$ model can overestimate the required drug dose by as much as $84 \%$ for non-passerines and $34 \%$ for passerines (Table 5). Alternatively, the seven-order phylogenetic model shows no significant difference between the doses it estimates and those calculated using BMR measured. This suggests that any difference observed between $B M R_{\text {measured }}$ and $B M R_{\text {calculated }}$ may simply be a matter of intra-animal differences and the use of species mean values. Although the seven-order model provides considerably more accurate dosing regimes than traditional approaches, there remains considerable within-order variation in BMR. When observed BMR values in the dataset are compared with the values predicted by the seven-order model, within-order variation is as follows: Galliformes: $64-111 \%$ of predicted values; Anseriformes: $48-131 \%$ of predicted values; Psittaciformes: $58-109 \%$ of predicted values; Strigiformes: $61-132 \%$ of predicted values; Columbiformes: $63-137 \%$ of predicted values; Passeriformes: $32-231 \%$ of predicted values. In the case of species for which BMR measurements do not exist, prediction accuracy can be further improved by using statistical approaches recently developed for testing hypotheses of metabolic adaptation. Garland \& Ives (2000) showed how independent contrasts (Felsenstein, 1985) can be used to calculate a phylogenetically independent regression and prediction intervals based on the exact position of a species within a phylogeny. Predicted BMR values generated using this approach are more strongly influenced by the BMRs of closely related species than by those of more phylogenetically distant taxa. The Garland \& Ives (2000) approach provides a powerful tool for predicting BMR, and will be particularly useful for estimating dosing regimes for species belonging to orders other than those included in the seven-order model, as well as for species belonging to orders that exhibit large intra-ordinal BMR variation (e.g. Passeriformes) (Fig. 4).

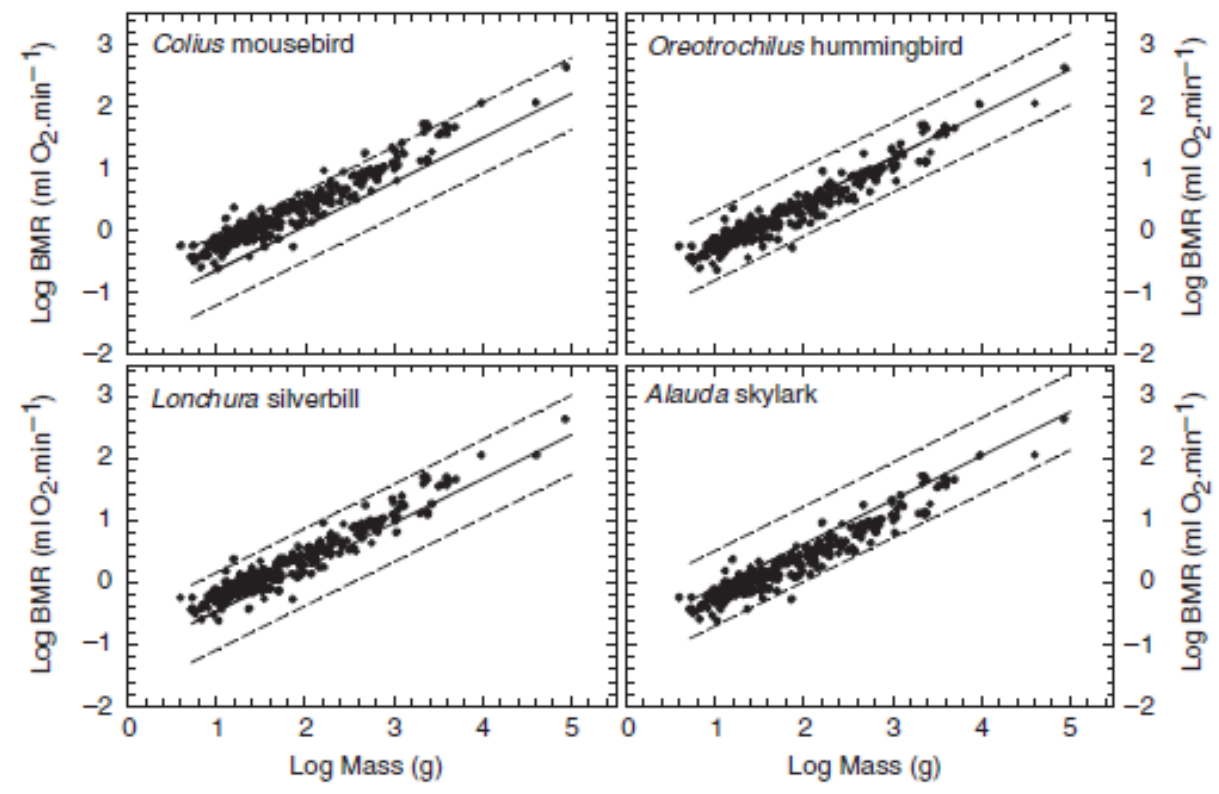


Figure 4 Phylogenetically independent regressions (solid lines) and 95\% prediction intervals for four arbitrarily chosen hypothetical avian species (two non-passerines and two passerines) calculated following Garland \& Ives (2000). The variation in the regression lines and prediction intervals illustrates how predicted basal metabolic rates (BMR, $\mathrm{mL} \mathrm{O}_{2} \mathrm{~min}^{-1}$ ) varies according to the position of a species within the phylogeny. Mass is in $\mathrm{kg}$.

Previous studies have tended statistically to remove phylogenetic variation between taxa as part of the process of analysing scaling relationships and/or correlating interpecific variation in BMR with climatic variables. In contrast, the primary focus of the present paper was understanding and quantifying these broad metabolic differences between higher-order taxa - differences that are vital for predicting appropriate therapeutic regimes. Even with an increasing amount of pharmacokinetic data from birds, the use of allometric extrapolation for the creation of drug regimens, based on dosage regimes from mammalian data, will continue to be common practice for Aves. Traditional allometric dose scaling is a good starting point when information from experimental work is not available. However, the data show that the addition of phylogenetic information accounting for species relationships is an important step in accurately determining drug dosages for bird species where direct pharmacokinetic information is not available. Thus, in order to determine the most appropriate metabolic scaling for a drug-dosing regime, it is best to use a multi-order phylogenetic model based on BMR.

\section{References}

- Baggot, J.D. (1982). Disposition and fate of drugs in the body. In Veterinary pharmacology and therapeutics: 36-69. Booth, N.H. \& Macdonald, L.E. (Eds). Ames, IA, USA: Iowa State University Press.

- Blomberg, S.P., Garland, T. Jr. \& Ives, A.R. (2003). Testing for phylogenetic signal in comparative data: behavioral traits are more labile. Evolution 57, 717-745.

- Brody, S. (1945). Bioenergetics and growth. New York: Reinhold Publishing Corporation.

- Burnham, K.P. \& Anderson, D.R. (2001). Kullback-Leibler information as a basis for strong inference in ecological studies. Wildl. Res. 28, 111-119.

- Burnham, K.P. \& Anderson, D.R. (2002). Model selection and multimodel inference: a practical information - theoretic approach, 2nd edn. New York: Springer.

- Chown, S.L., Marais, E., Terblanche, J.S., Klok, C.J., Lighton, J.R.B. \& Blackburn, T.M. (2007). Scaling of insect metabolic rate is inconsistent with the nutrient supply network model. Funct. Ecol. 21, 282-290.

- Felsenstein, J. (1985). Phylogenies and the comparative method. Am. Nat. 125, 1-15.

- Frappell, P.B., Hinds, D.S. \& Boggs, D.F. (2001). Scaling of respiratory variables and the breathing pattern in birds: an allometric and phylogenetic approach. Physiol. Biochem. Zool. 74, 75-89.

- Freckleton, R.P., Harvey, P.H. \& Pagel, M. (2002). Phylogenetic analysis and comparative data: a test and review of the evidence. Am. Nat. 160, 712-726. 
- Garland, T. Jr. \& Ives, A.R. (2000). Using the past to predict the present: confidence intervals for regression equations in phylogenetic comparative methods. Am. Nat. 155, 346-364.

- Garland, T. Jr., Midford, P.E. \& Ives, A.R. (1999). An introduction to phylogenetically based statistical methods, with a new method for confidence intervals on ancestral values. Am. Zool. 39, 374-388.

- Glazier, D.S. (2005). Beyond the '3/4-power law': variation in the intra- and interspecific scaling of metabolic rate in animals. Biol. Rev. 80, 1-52.

- Grafen, A. (1989). The phylogenetic regression. Proc. Roy. Soc. Lond. Ser. B 326, 119-157.

- Halsey, L.G., Butler, P.J. \& Blackburn, T.M. (2006). A phylogenetic analysis of the allometry of diving. Am. Nat. 167, 276-287.

- Harvey, P.H. \& Pagel, M.D. (1991). The comparative method in evolutionary biology. Oxford: Oxford University Press.

- Ihaka, R. \& Gentleman, R. (1996). R: a language for data analysis and graphics. J. Comput. Graph. Stat. 5, 299-314.

- Kleiber, M. (1932). Body size and metabolism. Hilgardia 6, 315-353.

- Kleiber, M. (1975). The fire of life, 2nd edn. New York, USA: Robert E. Kreiger.

- Lasiewski, R.C. \& Calder, W.A. (1971). A preliminary allometric analysis of respiratory variables in resting birds. Resp. Physiol. 11, 152-166.

- Lasiewski, R.C. \& Dawson, W.R. (1967). A re-examination of the relation between standard metabolic rate and body weight in birds. Condor 69, 13-23.

- Martins, E.P. \& Hansen, T.F. (1997). Phylogenies and the comparative method: a general approach to incorporating phylogenetic information into the analysis of interspecific data. Am. Nat. 149, 646-667.

- McKechnie, A.E., Freckleton, R.P. \& Jetz, W. (2006). Phenotypic plasticity in the scaling of avian basal metabolic rate. Proc. Roy. Soc. Lond. Ser. B 273, 931-937.

- McNab, B.K. (1997). On the utility of uniformity in the definition of basal rate of metabolism. Physiol. Zool. 70, 718-720.

- Paradis, E., Claude, J. \& Strimmer, K. (2004). APE: analysis of phylogenetics and evolution in R language. Bioinformatics 20, 289-290.

- Reynolds, P.S. \& Lee, R.M. (1996). Phylogenetic analysis of avian energetics: passerines and nonpasserines do not differ. Am. Nat. 147, 735-759.

- Rezende, E.L., Bozinovic, F. \& Garland, T. Jr. (2004). Climatic adaptation and the evolution of basal and maximum rates of metabolism in rodents. Evolution 58, 1361-1374.

- Ricklefs, R.E. \& Starck, J.M. (1996). Applications of phylogenetically independent contrasts: a mixed progress report. Oikos 77, 167-172.

- Sarrus, F. \& Rameaux, J. (1838). Rapport sur une mêmoire adresséàl'Académic royale de Médecine. Bull. Acad. R. Med. Paris 3, 1094 1100. (cited in Brody [1945] 1974).

- Schmidt-Nielsen, K. (1997). Animal physiology. UK: Cambridge University Press.

- Sedgwick, C.J., Pokras, M. \& Kaufman, G. (1990). Metabolic scaling: using estimated energy cost to extrapolate drug doses between different species and different individuals of diverse body size. Proc. Annu. Meet. AAZV 1990, 6062 . 
- Sibley, C.G. \& Ahlquist, J.E. (1990). Phylogeny and classification of birds: a study in molecular evolution. New Haven: Yale University Press.

- Sibley, C.G. \& Monroe, B.L. Jr. (1990). Distribution and taxonomy of birds of the world. New Haven, CT: Yale University Press.

- Suarez, R.K. (1996). Upper limits to mass-specific metabolic rates. Annu. Rev. Physiol. 58, 583-605.

- White, C.R., Blackburn, T.M., Martin, G.R. \& Butler, P.J. (2007). Basal metabolic rate of birds is associated with habitat temperature and precipitation, not primary productivity. Proc. Roy. Soc. Lond. Ser. B 274, 287-293.

- White, C.R., Phillips, N.F. \& Seymour, R.S. (2006). The scaling and temperature dependence of vertebrate metabolism. Biol. Lett. 2, 125-127.

- White, C.R. \& Seymour, R.S. (2004). Does BMR contain a useful signal? Mammalian BMR allometry and correlations with a selection of physiological, ecological and lifehistory variables. Physiol. Biochem. Zool. 77, 929-941.

- Withers, P.C. (1992). Comparative animal physiology, International edn. New York: Saunders College Publishing.

- Wolfensohn, S. \& Lloyd, M. (Eds). (2007). Wild animals, handbook of laboratory animal management and welfare, 3rd edn: 392-403. Oxford: Blackwell Publishing Ltd. Zar, J.H. (1999). Biostatistical analysis, 4th edn. Englewood Cliffs, NJ: Prentice-Hall. 